\title{
Assisted reproductive technology and the risk of preeclampsia: an updated systematic review and meta-analysis
}

\author{
Amir Almasi-Hashiani ${ }^{1}$, Reza Omani-Samani ${ }^{2}$, Maryam Mohammadi ${ }^{2}$, Payam Amini ${ }^{3}$, Behnaz Navid ${ }^{2}$, \\ Ahad Alizadeh ${ }^{2}$, Esmaeil Khedmati Morasae ${ }^{4}$ and Saman Maroufizadeh ${ }^{5^{*}}$ (D)
}

\begin{abstract}
Background: The objective of this systematic review and meta-analyses was to assess the risk of preeclampsia among women who conceived with assisted reproductive technology (ART).

Methods: We searched the ISI Web of Knowledge, Medline/PubMed, Scopus, and Embase (from inception to May 2017) for English language articles using a list of key words. In addition, reference lists from identified studies and relevant review articles were also searched. Data extraction was performed by two authors, and the study quality was assessed using the Newcastle-Ottawa Scale. Random-effects model meta-analysis was applied to pool the relative risks (RR) across studies.

Results: A total of 48 studies ( 5 case-control studies and 43 cohort studies) were included in this meta-analysis. The Cochran $Q$ test and $I^{2}$ statistics revealed substantial heterogeneity $\left(Q=26,313.92\right.$, d.f. $=47, p<0.001$ and $\left.I^{2}=99.8 \%\right)$. Meta-analysis showed a significant increase in preeclampsia in women who conceived by ART compared with those who conceived spontaneously $(\mathrm{RR}=1.71,95 \% \mathrm{Cl}=1.11-2.62, p=0.015)$.

Conclusions: The findings of this systematic review indicate that the use of ART treatment is associated with a 1. 71-fold increase in preeclampsia.
\end{abstract}

Keywords: Assisted reproductive technology, Preeclampsia, Infertility, Meta-analysis, Systematic review

\section{Background}

Assisted reproductive technologies (ART) are used to treat infertility problems and contain methods in which oocyte and sperm are manipulated in vitro [1]. The use of ART has increased exponentially worldwide and is responsible for over than one million births annually $[2,3]$. Having been treated by ART, the women who conceived had numerous adverse outcomes, both for themselves and the infants [3]. Previous studies have demonstrated that ART is associated with small for gestational age infants, preterm delivery, perinatal mortality, preeclampsia (PE), gestational diabetes, placenta previa, placental abruption, and cesarean delivery [4]. Of several adverse pregnancy consequences, hypertensive

\footnotetext{
* Correspondence: saman.maroufizadeh@gmail.com

${ }^{5}$ School of Nursing and Midwifery, Guilan University of Medical Sciences, Rasht, Iran

Full list of author information is available at the end of the article
}

disorders affect $6-8 \%$ of all pregnancies through gestational hypertension and PE $[5,6]$. In contrast to spontaneous pregnancy, pregnancies with ART are at an increased risk of PE [7]. It remained unclear whether either ART itself [in vitro fertilization (IVF), intracytoplasmic sperm injection (ICSI), intrauterine insemination (IUI), oocyte donation (OD), or embryo donation (ED)] or maternal risk factors associated with ART (that is, advanced maternal age, obesity, change of partner, longer interval between births, reduced smoking, and chronic hypertension) were related to increased risk of PE $[7,8]$. Some studies have shown the probability of the taking of some medications during pregnancy, such as low-dose aspirin, [9] prevents for PE in high-risk women [10-12]. Thus, identifying high-risk women during the early period of gestation will be worthwhile for the prevention and management of the pregnancy complications [13]. Finally, the lack of diagnostic criteria for pregnancy complications associated

(c) The Author(s). 2019 Open Access This article is distributed under the terms of the Creative Commons Attribution 4.0 International License (http://creativecommons.org/licenses/by/4.0/), which permits unrestricted use, distribution, and reproduction in any medium, provided you give appropriate credit to the original author(s) and the source, provide a link to the Creative Commons license, and indicate if changes were made. The Creative Commons Public Domain Dedication waiver (http://creativecommons.org/publicdomain/zero/1.0/) applies to the data made available in this article, unless otherwise stated. 
with hypertension, especially for PE, make the research in this field more complicated [14].

In the present paper, the authors conducted a comprehensive systematic review of ART procedures and PE. The aim of this review was to investigate whether ART mediated pregnancies (i.e., IUI, IVF, ICSI, OD, and ED) increased the incidence of PE in pregnancy compared with spontaneous pregnancies.

\section{Methods}

\section{Search strategy}

This meta-analysis was performed according to the PRISMA (Preferred Reporting Items for Systematic Reviews and Meta-Analyses) checklist [15]. We conducted a systematic literature search in Medline/ PubMed, Embase, Scopus, and the ISI Web of Knowledge from inception through June 2017 for studies examining the association between ART and PE. In addition, reference lists from all retrieved papers were checked. Table 1 provides more details about the search strategy.

\section{Inclusion and exclusion criteria}

We included published case-control studies and cohort studies evaluating the association between ART and PE risk. No geographic restrictions were used. The following types of studies were excluded: (a) non-English full-text studies, (b) animal studies, (c) repeated or overlapping studies, (d) reviews, meta-analysis and cross-sectional articles, case reports, editorials, and letters to the editor, (e) abstract-only publications or unpublished studies. There were five case-control studies added to the study. However, it was not substantially possible to estimate the relative risk (RR) with case-control design due to the fact that the marginal probabilities were not available; under the rare disease assumption, the odds ratio will be approximate the RR.

\section{Outcome and exposure}

In the present study, all types of ART treatments were considered as the interested exposure variable. Our outcome was PE defined as "elevated blood pressure (BP) (more than $140 / 100 \mathrm{mmHg})$ and proteinuria $(0.3 \mathrm{~g}$ over 24 hours or more)."

\section{Data extraction}

Two authors (MM and SM) independently extracted the following data from all studies meeting the inclusion criteria: first author's name, year of publication, location, study period, design, sample size, and study results. In addition, outcome data were extracted from each study in a $2 \times 2$ table, and the results were expressed as RR with their respective 95\% confidence intervals (CIs) [9].

\section{Quality assessment}

Two authors (MM and SM) independently assessed the quality of studies using the Newcastle-Ottawa Scale (NOS) [16]. This scale assesses methodology in three domains: (a) selection of study groups, (b) comparability of groups, and (c) ascertainment of exposure and outcomes. Total score ranged from 0 to 9 with a score of $\geq 8$ indicating high quality.

\section{Statistical analysis}

Statistical analysis was conducted using Stata version 13.0 (Stata Corp, College Station, TX, USA). The RR was used as the effect size of association across studies. The Cochran $\mathrm{Q}$ test and the $\mathrm{I}^{2}$ statistic were used to evaluate heterogeneity among studies [17]. Concerning the Cochrane $\mathrm{Q}$ test, $P<0.10$ was deemed statistically significant for heterogeneity. The $\mathrm{I}^{2}$ statistic indicates the percentage of total variation across studies that is due to heterogeneity rather than chance and is classified as mild (25\%), moderate (50\%), or high (75\%) [17]. The Galbraith plot was used to detect the potential sources of heterogeneity [18]. The pooled RR estimate and corresponding $95 \%$ CI were calculated by using the random-effect model incorporating between-study variability. The Begg's rank correlation test, Egger's weighted regression test, and visual inspection of a funnel plot were used to assess publication bias $[19,20]$. All tests were two-tailed and a $P$ value of $<0.05$ was deemed statistically significant.

\begin{tabular}{ll}
$\begin{array}{l}\text { Table } 1 \text { Search strategy for MEDLINE (MeSH, Medical Subject } \\
\text { Headings) }\end{array}$ \\
\hline 1 & Preeclampsia [Text Word]) \\
\hline 2 & Pre-Eclampsia [Text Word]) \\
3 & "Pre-Eclampsia" [Text Word]) \\
4 & "Pre-Eclampsia" [MeSH Terms] \\
5 & 1 OR 2 OR 3 OR 4 \\
6 & Reproductive Techniques, Assisted [Text Word] \\
7 & Reproductive Techniques, Assisted [MeSH Terms] \\
8 & 6 OR 7 \\
9 & Cohort Studies [Text Word] \\
10 & Cohort Studies [MeSH Terms] \\
11 & Retrospective Studies [Text Word] \\
12 & Retrospective Studies [MeSH Terms] \\
13 & Prospective Studies [Text Word] \\
14 & Prospective Studies [MeSH Terms] \\
15 & Case-Control Studies [Text Word] \\
16 & Case-Control Studies [MeSH Terms] \\
17 & 9 OR 10 OR 11 OR 12 OR 13 OR 14 OR 15 OR 16 \\
18 & 5 AND 8 AND 17 \\
\hline &
\end{tabular}




\section{Results}

Study selection

The process of study selection is illustrated in Fig. 1. A total of 1244 relevant papers were identified using diverse search strategies in four databases (113 from PubMed, 140 from Embase, 897 from Scopus, and 94 from Web of Knowledge) and three records of gray literature. After removing duplicates, 1057 papers remained, and 749 papers were deemed ineligible after title and abstract screening, and 308 relevant papers were considered for further screening through full-text reading. After the exclusion of all non-eligible studies ( $n=260$ ), a total of 48 studies (5 case-control studies and 43 cohort studies) were included in this meta-analysis.

\section{Study characteristics}

For each study, sample size, total number of ART and non-ART group, number of PE cases in each group, publication date, first author, target country, type of study, and participant mean age of each group were extracted. Cross-sectional studies and non-English studies were excluded from the meta-analysis. All of the primary studies were published between 1999 and 2017 and out of 48 studies, 11 were carried out in the United States, 11 in Asia, and 26 in Europe. The characteristics of studies considered in the meta-analysis are presented in Table 2.

\section{Quantitative data synthesis}

A total of 156,246 ART cases (with 14,560 cases of PE) and 6,558,249 non-ART cases (with 202,064 cases of PE) were included in the analysis. Risk ratios and their 95\% CIs were reported using the Mantel-Haenszel method. The relationship of ART and the risk of PE were estimated using the 48 primary included studies. The pooled estimate of $R R$ in this meta-analysis revealed that ART was significantly associated with a higher risk of $\mathrm{PE}$ (pooled $\mathrm{RR}=1.708,95 \% \mathrm{CI}=1.111-2.624$, $\mathrm{z}=2.44, p=0.015)$, that is, the PE risk in ART group was 1.687 times greater compared to the non-ART group (Fig. 2, Table 3).

\section{Heterogeneity analysis}

Chi-square analysis showed that there was substantial heterogeneity between primary studies (heterogeneity $x^{2}$ $=26,313.92, p<0.001, \mathrm{I}^{2}=99.8 \%$, and $\left.\tau^{2}=2.17\right)$. Therefore, we concluded that the random-effect model was

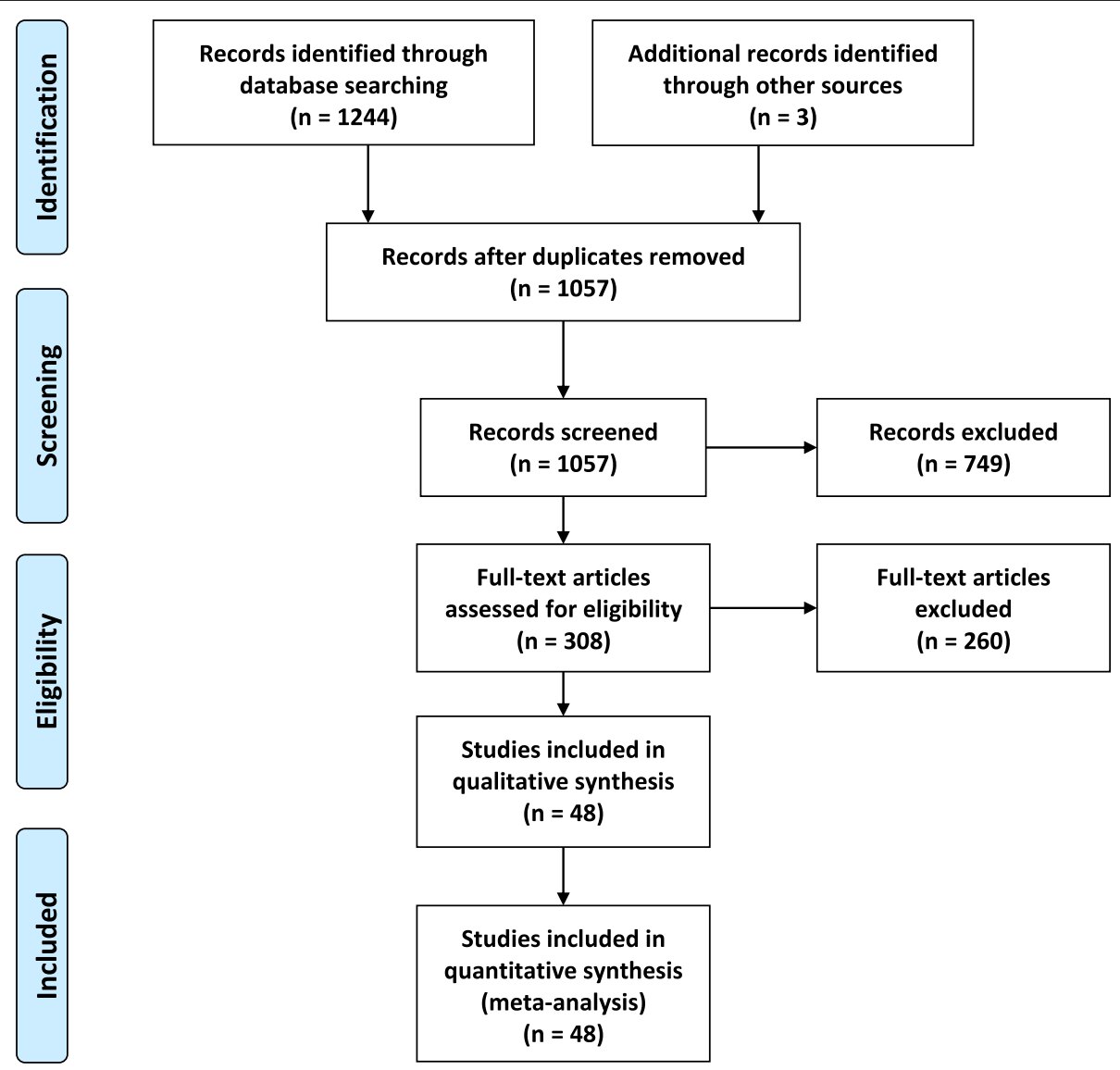

Fig. 1 Flow diagram of study process 
Table 2 Characteristics of the primary studies included in the meta-analysis

\begin{tabular}{|c|c|c|c|c|c|c|c|c|}
\hline Author & DOP & Country & Period & Design & PE in ART & ART group & PE in NART & NART group \\
\hline Julie Hoy [42] & 1999 & Australia & $1982-1995$ & Cohort & 131 & 1552 & 399 & 7717 \\
\hline O.Salha [43] & 1999 & UK & 1992-1997 & Cohort & 13 & 112 & 1 & 112 \\
\hline A.Geipel [44] & 2001 & Germany & 1995-1999 & Cohort & 6 & 114 & 11 & 114 \\
\hline Anne Lynch [45] & 2002 & USA & $1994-2000$ & Cohort & 27 & 198 & 40 & 330 \\
\hline Syeda Zaib-un-Nisa [46] & 2003 & Emirates & $1997-2001$ & Cohort & 4 & 36 & 4 & 96 \\
\hline Pinborg [47] & 2004 & Denmark & 1997 & Cohort & 71 & 870 & 49 & 566 \\
\hline Barbara Luke [48] & 2004 & USA & 1990-2002 & Cohort & 25 & 228 & 24 & 725 \\
\hline Bengt Kallen [49] & 2005 & Sweden & $1982-2001$ & Cohort & 978 & 13,261 & 55,728 & $2,013,633$ \\
\hline Fiona Thomson [50] & 2005 & Scotland & 1989-1999 & Cohort & 70 & 1437 & 556 & 21,688 \\
\hline Sonia Hernandez-Diaz [51] & 2006 & USA \& Canada & $1998-2006$ & Cohort & 18 & 349 & 115 & 4762 \\
\hline Erez [52] & 2006 & Israel & 1988-2002 & Cohort & 51 & 292 & 193 & 2336 \\
\hline Prefumo [53] & 2007 & UK & NA & Case Control & 1 & 31 & 1 & 62 \\
\hline Apantaku [24] & 2008 & UK & 1999-2004 & Cohort & 6 & 88 & 7 & 88 \\
\hline Chen [54] & 2009 & Canada & 2005 & Cohort & 34 & 1357 & 77 & 5190 \\
\hline Sun [55] & 2009 & Canada & 2004-2007 & Cohort & 31 & 2118 & 112 & 8420 \\
\hline Morcel [56] & 2010 & France & $2001-2005$ & Cohort & 12 & 104 & 13 & 173 \\
\hline Miyake [57] & 2010 & Japan & $2005-2007$ & Cohort & 15 & 20 & 111 & 230 \\
\hline Suzuki [58] & 2010 & Japan & $2000-2007$ & Cohort & 4 & 64 & 9 & 87 \\
\hline Lehnen [28] & 2011 & Germany & $2000-2009$ & Cohort & 10 & 74 & 8 & 305 \\
\hline Yang [59] & 2011 & Korea & 1995-2008 & Cohort & 9 & 67 & 22 & 143 \\
\hline Kuivasaari-Pirinen [60] & 2012 & Finland & $1996-2007$ & Cohort & 16 & 255 & 967 & 26,870 \\
\hline Bamberg [61] & 2012 & Germany & 1998-2008 & Cohort & 14 & 426 & 24 & 813 \\
\hline Lubovnik [62] & 2012 & Slovenia & $1997-2009$ & Case Control & 55 & 246 & 126 & 477 \\
\hline Sazonova [63] & 2012 & Sweden & $2002-2006$ & Cohort & 520 & 11,292 & 15,984 & 571,914 \\
\hline Mohammed [64] & 2012 & Qatar & 2002-2011 & Cohort & 27 & 145 & 30 & 175 \\
\hline Le Ray [65] & 2012 & France & $2008-2010$ & Cohort & 24 & 144 & 9 & 236 \\
\hline Emily Werder [66] & 2013 & USA & $2002-2008$ & Cohort & 45 & 215 & 62 & 232 \\
\hline Sara S. Malchau [67] & 2013 & Denmark & $1995-2010$ & Cohort & 1185 & 24,305 & 2519 & 56,022 \\
\hline Rocio Revello [68] & 2013 & Italy & $2000-1010$ & Cohort & 28 & 88 & 14 & 59 \\
\hline Sari Raisanen [69] & 2013 & Finland & $2006-2010$ & Cohort & 90 & 5647 & 3138 & 285,357 \\
\hline Alex Fong [70] & 2014 & USA & 2009 & Case Control & 29 & 551 & 7487 & 406,334 \\
\hline Nathan S. Fox [71] & 2014 & USA & $2005-2012$ & Case Control & 61 & 376 & 15 & 137 \\
\hline Tandberg [39] & 2014 & Norway & $1967-2009$ & Cohort & 5516 & 8549 & 24,971 & 493,217 \\
\hline Tali Silberstein [72] & 2014 & Israel & NA & Cohort & 113 & 1294 & 7889 & 171,513 \\
\hline Cagrı Arıoglu Aydın [23] & 2015 & Istanbul & $2007-2010$ & Cohort & 13 & 137 & 46 & 133 \\
\hline Anne-Maude Morency [73] & 2015 & Canada & $2000-2013$ & Cohort & 39 & 181 & 4 & 49 \\
\hline Robert Johnston [27] & 2015 & USA & 2009 & Cohort & 29 & 551 & 7847 & 406,334 \\
\hline Malinda S. Lee [74] & 2015 & USA & $2006-2008$ & Cohort & 17 & 108 & 176 & 2284 \\
\hline Bay [75] & 2016 & Denmark & 1999-2013 & Cohort & 2675 & 30,418 & 37,531 & 896,448 \\
\hline DoPierala [76] & 2016 & UK & 1992-2009 & Cohort & 203 & 3188 & 2341 & 52,443 \\
\hline Nejdet [77] & 2016 & Sweden & $2003-2012$ & Cohort & 1156 & 27,084 & 27,912 & 999,804 \\
\hline Zhu [78] & 2016 & China & $2006-2014$ & Cohort & 98 & 2641 & 110 & 5282 \\
\hline Vikstrom [79] & 2016 & Sweden & $1988-2012$ & Case Control & 607 & 10,412 & 822 & 18,624 \\
\hline Ben-Yaakov [80] & 2016 & Israel & $1988-2012$ & Cohort & 378 & 4153 & 4471 & 95,138 \\
\hline Sun [81] & 2016 & China & 2010-2014 & Cohort & 42 & 411 & 54 & 742 \\
\hline Valenzuela-Alcaraz [26] & 2016 & Spain & $2004-2010$ & Cohort & 6 & 488 & 0 & 200 \\
\hline Rizzo [82] & 2016 & Italy & $2007-2014$ & Cohort & 17 & 249 & 6 & 260 \\
\hline Guilbaud [25] & 2017 & France & 2010-2014 & Cohort & 41 & 303 & 32 & 369 \\
\hline
\end{tabular}




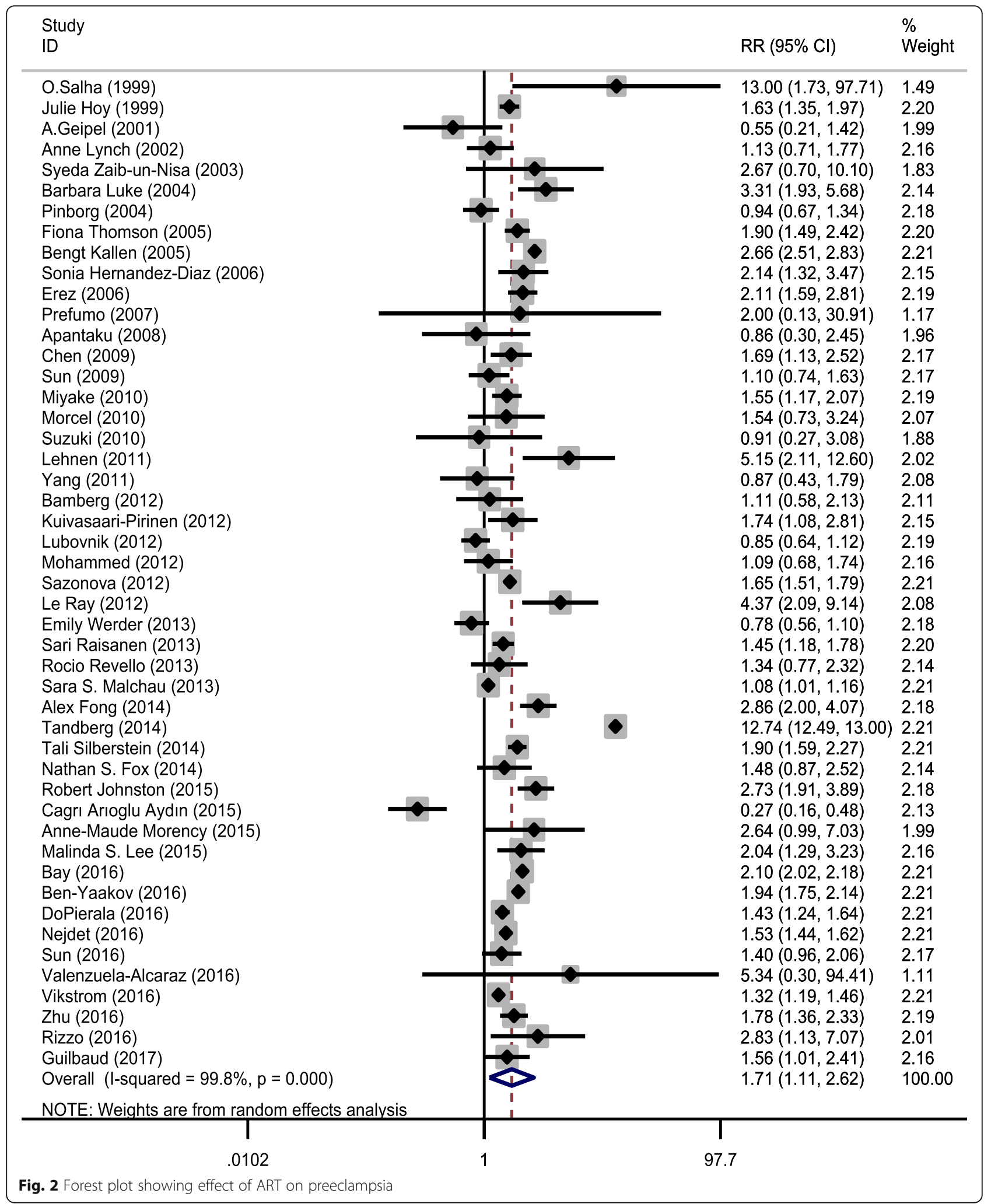

used to pool the studies. To discover the source of heterogeneity, subgroup analysis was carried out on the basis of study design (case control and cohort), study region (United States, Asia, and Europe), and study period (1999-2010 and 2010-2017) (Figs. 3, 4 and 5, and Table 3). After subgroup analysis, heterogeneity 
Table 3 Summary of meta-analysis results and subgroups analysis

\begin{tabular}{|c|c|c|c|c|c|c|c|c|}
\hline \multirow[t]{2}{*}{ Groups } & \multirow[t]{2}{*}{ Studies } & \multicolumn{4}{|c|}{ Test of association } & \multicolumn{3}{|c|}{ Heterogeneity } \\
\hline & & RR $(95 \% \mathrm{Cl})$ & $P$ value & Model & Z & Chi square & $P$ value & I square \\
\hline Total studies & 48 & $1.71(1.11-2.62)$ & 0.015 & Random & 2.44 & $26,313.92$ & $<0.001$ & $99.8 \%$ \\
\hline \multicolumn{9}{|c|}{ Subgroup analyses } \\
\hline \multicolumn{9}{|l|}{ Study design } \\
\hline Cohort & 43 & $1.73(1.10-2.72)$ & 0.018 & Random & 2.36 & $25,159.19$ & $<0.001$ & $99.8 \%$ \\
\hline Case control & 5 & $1.46(0.97-2.20)$ & 0.070 & Random & 1.81 & 28.38 & $<0.001$ & $85.9 \%$ \\
\hline \multicolumn{9}{|l|}{ Time Period } \\
\hline 1999-2010 & 18 & $1.64(1.31-2.05)$ & $<0.001$ & Random & 4.29 & 117.09 & $<0.001$ & $85.5 \%$ \\
\hline 2010-2017 & 30 & $1.74(0.97-3.09)$ & 0.062 & Random & 1.87 & $25,671.51$ & $<0.001$ & $99.9 \%$ \\
\hline \multicolumn{9}{|l|}{ Region } \\
\hline Asia & 11 & $1.71(1.53-1.92)$ & $<0.001$ & Random & 9.38 & 17.12 & 0.072 & $41.6 \%$ \\
\hline Europe & 26 & $1.74(0.95-3.21)$ & 0.075 & Random & 1.78 & $25,090.51$ & $<0.001$ & $99.9 \%$ \\
\hline America & 11 & $1.78(1.31-2.41)$ & $<0.001$ & Random & 3.70 & 52.30 & $<0.001$ & $80.9 \%$ \\
\hline
\end{tabular}

RR Relative Risk, CI Confidence Interval

across studies did not decrease effectively; therefore, all estimations of RR were made by the random-effect model.

\section{Risk of publication bias}

Both graphical and statistical assessments were performed to check for the presence of publication bias. On the basis of the asymmetrical funnel plot (Fig. 6) and Begg's test $(p=0.001)$, there was evidence of publication bias in this study. Accordingly, we excluded non-English papers from the meta-analysis and this can lead to bias.

\section{Discussion}

This study aimed to evaluate whether several studies agree with the effect of ART on the presence of PE. In this meta-analysis, 6,714,495 cases were recruited (156,246 ART cases and 6,558,249 non-ART cases). To detect the risk of PE regarding the use of ART, the heterogeneity among the studies was assessed, and the appropriate statistical tool was applied. To increase the validity of the results, the risk of publication bias was checked. Analysis of the important subgroups, such as publication date, type of study, and region, was performed.

Similar to the results achieved from our study, most of the studies have introduced the use of ART as a significant risk factor for placental abruption, low and very low birth weight in infants, placenta previa, gestational hypertension, risk of cesarean section, and PE [21, 22]. However, not all the investigators agree with the adverse effect of ART on pregnancy outcomes [23, 24]. Most of previous studies have proven the important impact of using ART on PE [25-28]. The positive association between ART and PE is well demonstrated by the included studies. Regarding the magnitude of the effect size, the pooled results from case-control studies were in compliance with those of cohort studies. However, in contrast to the cohort studies, the pooled RR from the case-control studies was not statistically significant. Moreover, the impact of ART on PE did not differ in two distinct periods of time (2010 as the cut-off point). Although consistent results were observed among different regions, the pooled RR from the European studies was not significant. Moreover, the effect size of the Asian and United States studies was higher than that of Europe.

We found that the use of ART was a significant risk factor for PE. The application of ART has increased across many countries around the world as a way to cope with infertility problems. The prevalence of using ART differs among countries. Annually, more than 1.5\% of all births in the United States are the result of ART. The prevalence of PE is almost 10\% in Africa and 15\% in China [29-32]. In addition, the prevalence of PE has an increasing slope. Numerous factors, including the use of ART, hypertension, diabetes, obesity, and early diagnosis problems, are responsible for the ascending trend of $\mathrm{PE}$ prevalence [30, 33]. The adverse outcomes after ART cause damage to body organs, such as the kidney and liver, through PE as well as maternal mortality, perinatal deaths, preterm birth, intrauterine growth restriction, bleeding problems, and fetal growth retardation [34, 35]. In addition to ART, other factors such as anti-phospholipid syndrome, previous $\mathrm{PE}$, family history of $\mathrm{PE}$, insulin-dependent diabetes, obesity, multiple pregnancies, and nulliparity can affect PE [36]. The mechanism in which ART affects PE is not well known. However, it has been argued that abnormal placentation can influence PE. In some ART procedures, the blood flow is compromised and is diminished, which is then followed by obstetric complications. Moreover, placental 







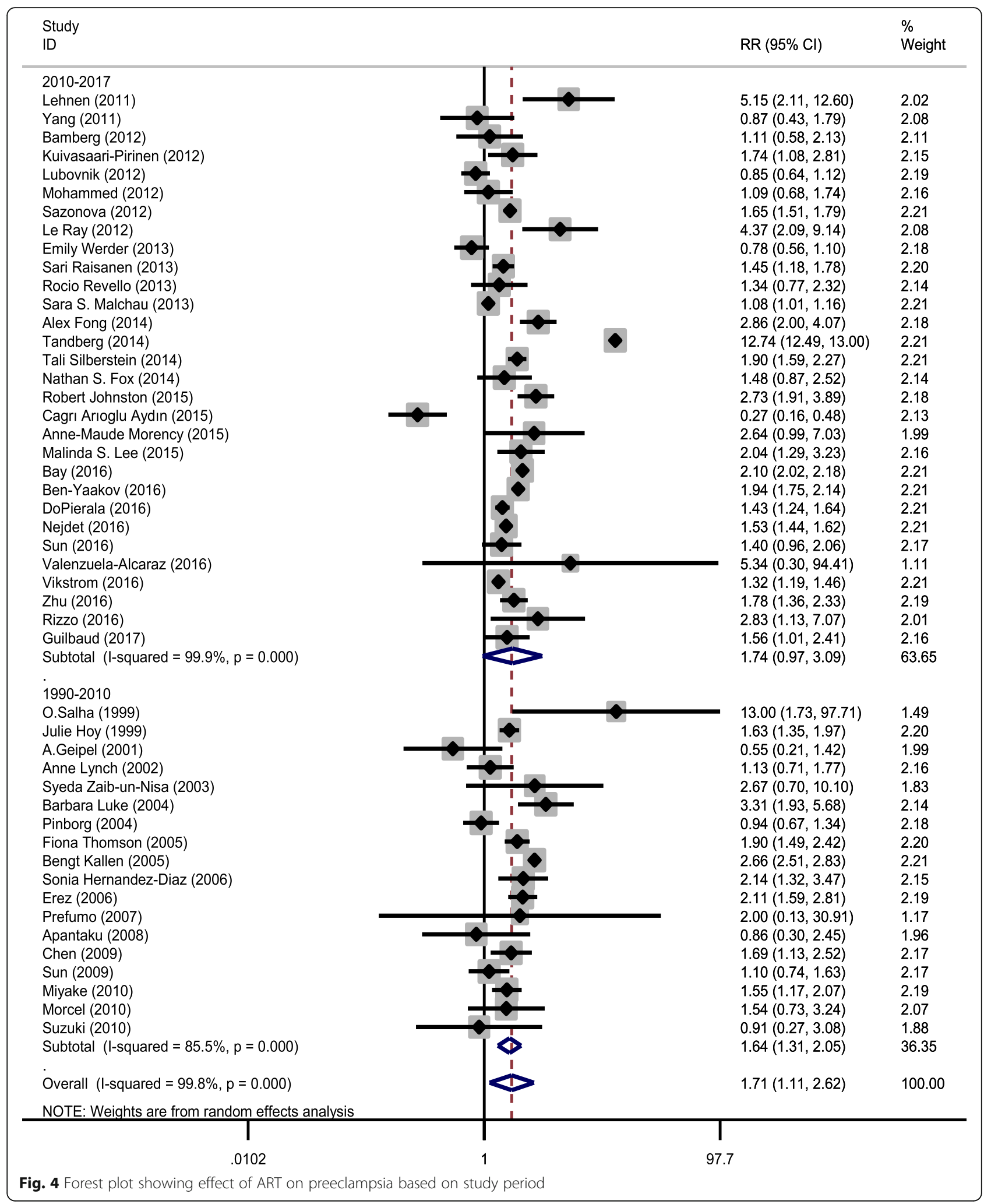

insufficiency is caused by the transfer of the conceptus into the uterine cavity and the impact of the altered hormonal environment in the endometrium where the development of the maternal-fetal interface can be influenced [37, 38]. It has been argued that ART may have epigenetic effects. The pregnancies from ART are 


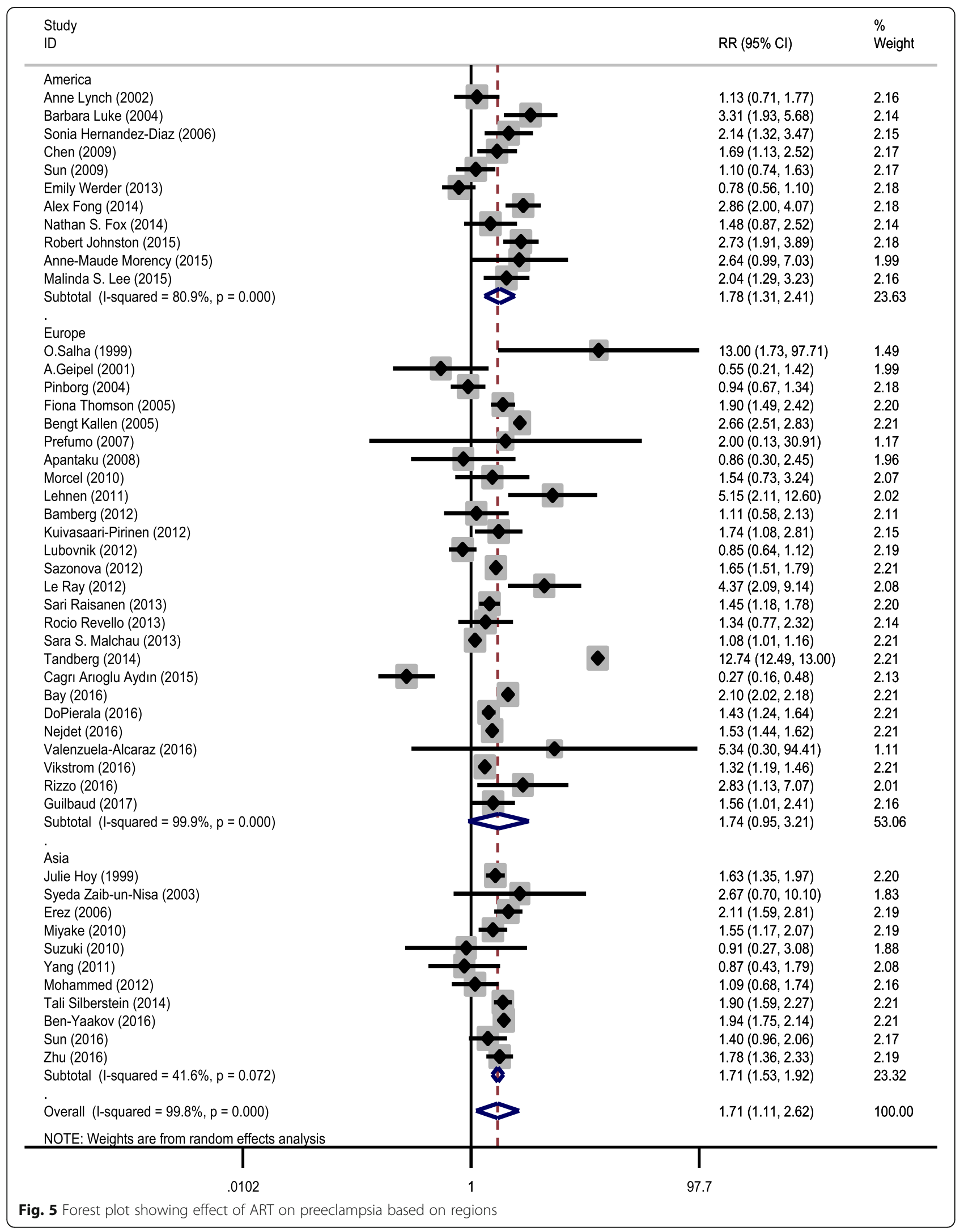




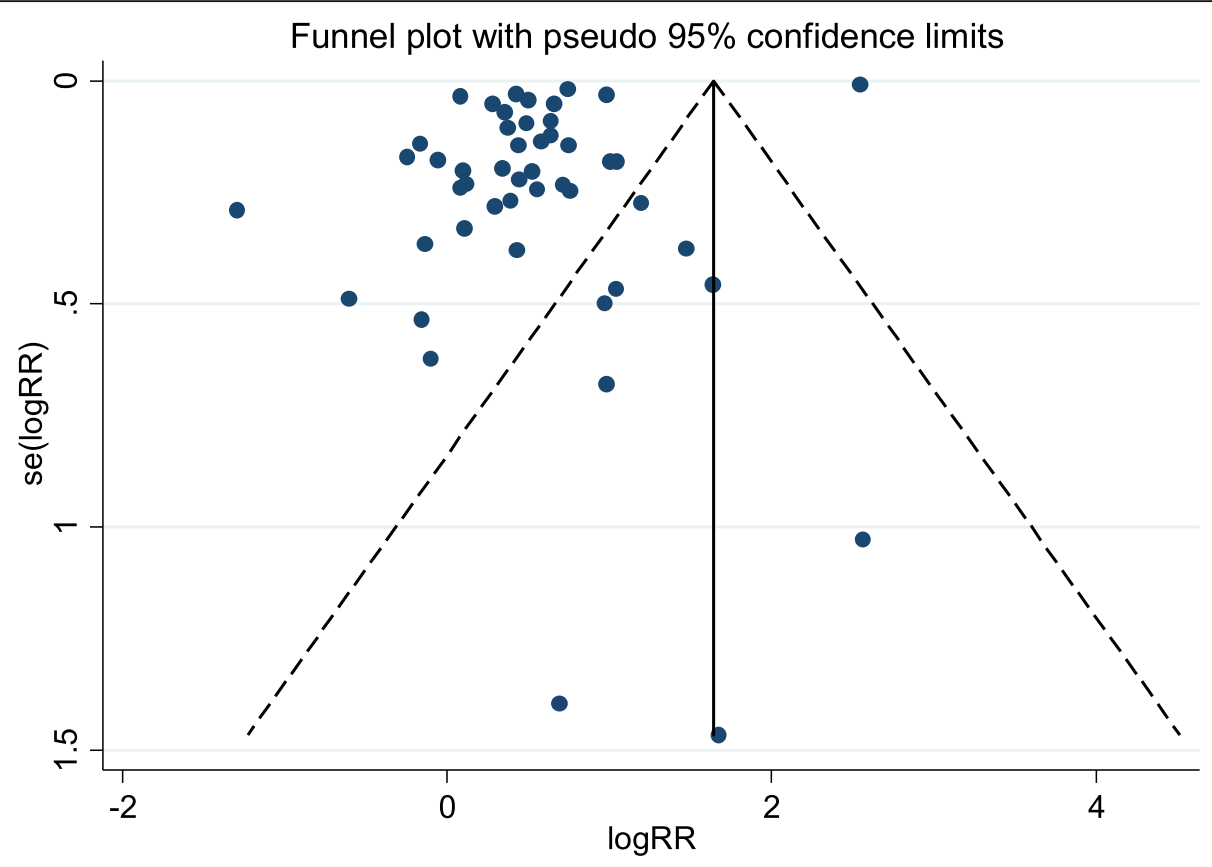

Fig. 6 Funnel plots of studies examining the association between ART and preeclampsia

associated with PE through oxidative stress. In addition, ART has several types of reproductive dysfunction with the same strength as miscarriages. Recurrent spontaneous miscarriages, along with infertility treatments, increase the risk of $\mathrm{PE}$ in comparison to those without treatment [39]. Nonetheless, the excess RR in the association between ART and PE can be caused by multiple factors, such as previous fertility complications, lifestyle, smoking habits, long inter-birth intervals, multiple pregnancy, and advanced maternal age [39]. However, there are many other causal factors associated with infertility itself in which the relationship between PE and ART can be argued.

Thomopoulos et al. assessed the risk of hypertensive disorders in pregnancy following ART using an overview of the studies conducted from 1978 to 2016 [40]. Their study included papers from PubMed and the Cochrane Collaboration Library databases with a total of 32 papers with PE as an outcome. The present meta-analysis has added primary studies from other databases such as Embase, Scopus, and ISI Web of Knowledge with a total number of 48 papers up to June 2017.

The controversy of using statistical tools to determine the magnitude of heterogeneity in meta-analysis has several potential causes, including sample size and number of the included studies, the period of time, the geographical patterns, the level of development, and the types of studies, etc. In this regard, a non-significant result from a chi-square test must not be taken as evidence of a lack of heterogeneity.
Furthermore, the chi-square test is very powerful when many studies are included in a meta-analysis. The other statistical tool to detect heterogeneity, the $\mathrm{I}^{2}$ value, depends on the magnitude of the rates [41]. In our meta-analysis, the result of the chi-square test was confirmed by the $\mathrm{I}^{2}$ test. Except for a region of Asia, significant heterogeneities were observed among the pooled and subgroup RRs. The source of heterogeneities may be due to the diversity in the ethnic and cultural conditions and uneven development regions.

However, this study has some limitations. Almost every meta-analysis study deals with uncontrolled confounders. Researchers are not able to control the analysis for the confounders unless the proper information is presented by the original articles. To overcome this problem, "individual patient or participant data (IPD)" is suggested in which requires the detailed information and data-sets from every single original article and it is not applicable in most of the cases regarding that the authors (original articles) might not be interested to present their data and other potential reasons.

This systematic review has several limitations. First, the most important limitation for this study as for other systematic review is the lack of data for subgroup analysis based on type of pregnancy (singleton versus twin pregnancy) or for data analysis controlling for known confounders. Second, our study included only English full-text papers. However, globally published papers might present higher quality research compared with those of local origin. 


\section{Conclusion}

The present systematic review and meta-analysis revealed that the use of ART increases the risk of PE considerably. More attention must be paid to Asia and the United States, where the association is stronger and significant.

\section{Abbreviations}

ART: Assisted Reproductive Technology; Cl: Confidence Interval; PE: Preeclampsia; RR: Relative Risk

\section{Acknowledgements}

Not applicable.

\section{Funding}

This research did not receive any specific grant from any agency in the public, commercial, or not-for-profit sector. Esmaeil Khedmati Morasae is part-funded by the National Institute for Health Research Collaboration for Leadership in Applied Health Research and Care, North West Coast (NIHR CLAHRC NWC). The views expressed are those of the author and not necessary those of the NHS, NIHR or Department of Health.

\section{Availability of data and materials}

The datasets used and/or analyzed during the current study available from the corresponding author on reasonable request.

\section{Authors' contributions}

$\mathrm{SM}, \mathrm{ROS}$, and $\mathrm{AAH}$ conceived the study. MM, PA, BN, and AA collected the data. All of the authors contributed equally to the writing of the manuscript. $\mathrm{AAH}$ and EKM analyzed the data, and all authors revised the manuscript and approved the final version.

\section{Ethics approval and consent to participate}

Not applicable.

\section{Consent for publication}

Not applicable.

\section{Competing interests}

The authors declare that they have no competing interests.

\section{Publisher's Note}

Springer Nature remains neutral with regard to jurisdictional claims in published maps and institutional affiliations.

\section{Author details \\ ${ }^{1}$ Department of Epidemiology, School of Health, Arak University of Medical Sciences, Arak, Iran. ${ }^{2}$ Department of Epidemiology and Reproductive Health, Reproductive Epidemiology Research Center, Royan Institute for Reproductive Biomedicine, ACECR, Tehran, Iran. ${ }^{3}$ Department of Biostatistics and Epidemiology, School of Public Health, Ahvaz Jundishapur University of Medical Sciences, Ahvaz, Iran. ${ }^{4}$ Institute of Psychology, Health, and Society, Department of Health Services Research, University of Liverpool, Liverpool, UK. ${ }^{5}$ School of Nursing and Midwifery, Guilan University of Medical Sciences, Rasht, Iran.}

Received: 11 January 2018 Accepted: 12 April 2019

Published online: 02 May 2019

References

1. Zegers-Hochschild F, Adamson GD, Dyer S, Racowsky C, de Mouzon J, Sokol R, Rienzi L, Sunde A, Schmidt L, Cooke ID, et al. The International Glossary on Infertility and Fertility Care, 2017. Fertil Steril. 2017;108(3):393-406.

2. Davies M, Rumbold A, Moore V. Assisted reproductive technologies: a hierarchy of risks for conception, pregnancy outcomes and treatment decisions. J Dev Orig Health Dis. 2017:8(4):443-7.

3. Stephen EH, Chandra A, King RB. Supply of and demand for assisted reproductive technologies in the United States: clinic-and population-based data, 1995-2010. Fertil Steril. 2016;105(2):451-8.
4. Stern JE, Luke B, Tobias M, Gopal D, Hornstein MD, Diop H. Adverse pregnancy and birth outcomes associated with underlying diagnosis with and without assisted reproductive technology treatment. Fertil Steril. 2015;103(6):1438-45.

5. Program NHBPE. Report of the national high blood pressure education program working group on high blood pressure in pregnancy. Am J Obstet Gynecol. 2000;183(1):s1-s22.

6. Paré E, Parry S, McElrath TF, Pucci D, Newton A, Lim K-H. Clinical risk factors for preeclampsia in the 21st century. Obstet Gynecol. 2014;124(4):763-70.

7. Sibai B. Subfertility/infertility and assisted reproductive conception are independent risk factors for pre-eclampsia. BJOG. 2015;122(7):923.

8. Sibai B, Dekker G, Kupferminc M. Pre-eclampsia. Lancet. 2005;365(9461):785-99.

9. Murray CJL, Vos T, Lozano R, Naghavi M, Flaxman AD, Michaud C, Ezzati M, Shibuya K, Salomon JA, Abdalla S, et al. Disability-adjusted life years (DALYs) for 291 diseases and injuries in 21 regions, 1990-2010: a systematic analysis for the global burden of disease study 2010. Lancet. 2012;380(9859):2197-223.

10. Askie LM, Duley L, Henderson-Smart DJ, Stewart LA. Antiplatelet agents for prevention of pre-eclampsia: a meta-analysis of individual patient data. Lancet. 2007;369(9575):1791-8

11. Villa P, Kajantie E, Räikkönen K, Pesonen AK, Hämäläinen E, Vainio M, Taipale $P$, Laivuori $\mathrm{H}$. Aspirin in the prevention of pre-eclampsia in high-risk women: a randomised placebo-controlled PREDO trial and a meta-analysis of randomised trials. BJOG. 2013;120(1):64-74.

12. Women's NCCf, Health Cs: Hypertension in pregnancy: the management of hypertensive disorders during pregnancy. 2010.

13. Muto H, Yamamoto R, Ishii K, Kakubari R, Takaoka S, Mabuchi A, Mitsuda N. Risk assessment of hypertensive disorders in pregnancy with maternal characteristics in early gestation: a single-center cohort study. Taiwan J Obstet Gynecol. 2016;55(3):341-5.

14. Tranquilli A, Dekker G, Magee L, Roberts J, Sibai B, Steyn W, Zeeman G, Brown $\mathrm{M}$. The classification, diagnosis and management of the hypertensive disorders of pregnancy: a revised statement from the ISSHP. Pregnancy Hypertens. 2014:4(2):97-104.

15. Moher D, Liberati A, Tetzlaff J, Altman DG. Preferred reporting items for systematic reviews and meta-analyses: the PRISMA statement. Ann Intern Med. 2009;151(4):264-9.

16. Wells G, Shea B, O'Connell D, Peterson J, Welch V, Losos M. The NewcastleOttawa Scale (NOS) for assessing the quality if nonrandomized studies in meta-analyses. 2010. http://www.ohri.ca/programs/clinical_epidemiology/ oxford.asp.

17. Higgins J, Thompson SG. Quantifying heterogeneity in a meta-analysis. Stat Med. 2002;21(11):1539-58.

18. Galbraith R. A note on graphical presentation of estimated odds ratios from several clinical trials. Stat Med. 1988;7(8):889-94.

19. Begg CB, Mazumdar M. Operating characteristics of a rank correlation test for publication bias. Biometrics. 1994:1088-101.

20. Egger M, Smith GD, Schneider M, Minder C. Bias in meta-analysis detected by a simple, graphical test. BMJ. 1997;315(7109):629-34.

21. Shevell T, Malone FD, Vidaver J, Porter TF, Luthy DA, Comstock CH, Hankins GD, Eddleman K, Dolan S, Dugoff L. Assisted reproductive technology and pregnancy outcome. Obstet Gynecol. 2005;106(5, Part 1):1039-45.

22. Stephansson O, Kieler H, Granath F, Falconer H. Endometriosis, assisted reproduction technology, and risk of adverse pregnancy outcome. Hum Reprod. 2009:24(9):2341-7.

23. Arıoğlu Aydın Ç, Aydın S, Serdaroğlu H. Multifetal gestations with assisted reproductive technique before the single-embryo transfer legislation: obstetric, neonatal outcomes and congenital anomalies. J Matern Fetal Neonatal Med. 2016:29(15):2474-9.

24. Apantaku O, Chandrasekaran I, Bentick B. Obstetric outcome of singleton pregnancies achieved with in vitro fertilisation and intracytoplasmic sperm injection: experience from a district general hospital. J Obstet Gynaecol. 2008;28(4):398-402.

25. Guilbaud L, Santulli P, Studer E, Gayet V, Goffinet F, Le Ray C: Impact of oocyte donation on perinatal outcome in twin pregnancies. Fertil Steril. 2017;107(4): 948-53.

26. Valenzuela-Alcaraz B, Crispi F, Manau D, Cruz-Lemini M, Borras A, Balasch J, Gratacos E. J Matern fetal neonatal med. J Matern Fetal Neonatal Med. 2016; 29(23):3879-84.

27. Johnston R, Fong A, Lovell S, Sobolewski PS, Rad S, Turner A. Demographic and obstetric outcomes of pregnancies conceived by assisted reproductive technology (ART) compared to non-ART pregnancies. J Bras Reprod Assist. 2015;19(1):16-20. 
28. Lehnen H, Schafer S, Reineke T, Puchooa A, Maiwald R, Zechner U. Twin pregnancies conceived spontaneously and by ART (assisted reproductive technologies) - a retrospective analysis and review. Geburtshilfe Frauenheilkd. 2011;71(8):669-76.

29. Nakimuli A, Chazara O, Byamugisha J, Elliott AM, Kaleebu P, Mirembe F, Moffett A. Pregnancy, parturition and preeclampsia in women of African ancestry. Am J Obstet Gynecol. 2014;210(6):510-520. e511.

30. Ananth CV, Keyes KM, Wapner RJ. Pre-eclampsia rates in the United States, 1980-2010: age-period-cohort analysis. BMJ. 2013;347:f6564.

31. Ye C, Ruan Y, Zou L, Li G, Li C, Chen Y, Jia C, Megson IL, Wei J, Zhang W. The 2011 survey on hypertensive disorders of pregnancy (HDP) in China: prevalence, risk factors, complications, pregnancy and perinatal outcomes. PLoS One. 2014;9(6):e100180

32. Sunderam S, Chang J, Flowers L, Kulkarni A, Sentelle G, Jeng G, Macaluso M. Assisted reproductive technology surveillance-United States, 2006. MMWR Surveill Summ. 2009;58(5):1-25.

33. Jeyabalan A. Epidemiology of preeclampsia: impact of obesity. Nutr Rev. 2013;71(suppl 1):S18-25.

34. Noris M, Perico N, Remuzzi G. Mechanisms of disease: pre-eclampsia. Nat Rev Nephrol. 2005;1(2):98-114.

35. Redman CW, Sargent IL. Latest advances in understanding preeclampsia. Science. 2005;308(5728):1592-4.

36. English FA, Kenny LC, McCarthy FP. Risk factors and effective management of preeclampsia. Integr Blood Press Control. 2015;8:7.

37. Daniel Y, Schreiber L, Geva E, Amit A, Pausner D, Kupferminc M, Lessing J. Do placentae of term singleton pregnancies obtained by assisted reproductive technologies differ from those of spontaneously conceived pregnancies? Hum Reprod. 1999;14(4):1107-10.

38. Thomopoulos C, Tsioufis C, Michalopoulou H, Makris T, Papademetriou V, Stefanadis C. Assisted reproductive technology and pregnancy-related hypertensive complications: a systematic review. J Hum Hypertens. 2013;27(3):148.

39. Tandberg A, Klungsøyr K, Romundstad L, Skjaerven R. Pre-eclampsia and assisted reproductive technologies: consequences of advanced maternal age, interbirth intervals, new partner and smoking habits. BJOG. 2015; 122(7):915-22.

40. Thomopoulos C, Salamalekis G, Kintis K, Andrianopoulou I, Michalopoulou H, Skalis G, Archontakis S, Argyri O, Tsioufis C, Makris TK, et al. Risk of hypertensive disorders in pregnancy following assisted reproductive technology: overview and meta-analysis. J Clin Hypertens. 2017;19(2):173-83.

41. Higgins JP, Green S. Cochrane handbook for systematic reviews of interventions. Hoboken: Wiley; 2011.

42. Hoy J, Venn A, Halliday J, Kovacs G, Waalwyk K. Perinatal and obstetric outcomes of donor insemination using cryopreserved semen in Victoria, Australia. Hum Reprod. 1999;14(7):1760-4.

43. Salha O, Sharma V, Dada T, Nugent D, Rutherford A, Tomlinson A, Philips S, Allgar $V$, Walker J. The influence of donated gametes on the incidence of hypertensive disorders of pregnancy. Hum Reprod. 1999;14(9):2268-73.

44. Geipel A, Ludwig M, Germer U, Katalinic A, Diedrich K, Gembruch U. Uterine artery Doppler velocimetry and the outcome of pregnancies resulting from ICSI. Hum Reprod. 2001;16(7):1397-402.

45. Lynch A, McDuffie R, Murphy J, Faber K, Orleans M. Preeclampsia in multiple gestation: the role of assisted reproductive technologies. Obstet Gynecol. 2002;99(3):445-51.

46. Zaib-un-Nisa S, Ghazal-Aswad S, Badrinath P. Outcome of twin pregnancies after assisted reproductive techniques - a comparative study. Eur J Obstet Gynecol Reprod Biol. 2003;109(1):51-4.

47. Pinborg A, Loft A, Schmidt L, Langhoff-Roos J, Andersen AN. Maternal risks and perinatal outcome in a Danish national cohort of 1005 twin pregnancies: the role of in vitro fertilization. Acta Obstet Gynecol Scand. 2004;83(1):75-84.

48. Luke B, Brown MB, Nugent C, Gonzalez-Quintero VH, Witter FR, Newman RB. Risk factors for adverse outcomes in spontaneous versus assisted conception twin pregnancies. Fertil Steril. 2004;81(2):315-9.

49. Källén B, Finnström O, Nygren K, Otterblad Olausson P, Wennerholm UB. In vitro fertilisation in Sweden: obstetric characteristics, maternal morbidity and mortality. BJOG. 2005;112(11):1529-35.

50. Thomson F, Shanbhag S, Templeton A, Bhattacharya S. Obstetric outcome in women with subfertility. BJOG. 2005;112(5):632-7.

51. Hernández-Díaz S, Werler MM, Mitchell AA. Gestational hypertension in pregnancies supported by infertility treatments: role of infertility, treatments, and multiple gestations. Fertil Steril. 2007;88(2):438-45.
52. Erez O, Vardi IS, Hallak M, Hershkovitz R, Dukler D, Mazor M. Preeclampsia in twin gestations: association with IVF treatments, parity and maternal age. J Matern Fetal Neonatal Med. 2006;19(3):141-6.

53. Prefumo F, Fratelli N, Soares S, Thilaganathan B. Uterine artery Doppler velocimetry at 11-14 weeks in singleton pregnancies conceived by assisted reproductive technology. Ultrasound Obstet Gynecol. 2007;29(2):141-5.

54. Chen XK, Wen SW, Bottomley J, Smith GN, Leader A, Walker MC. In vitro fertilization is associated with an increased risk for preeclampsia. Hypertension in pregnancy. 2009;28(1):1-12.

55. Sun LM, Walker MC, Cao HL, Yang QY, Duan T, Kingdom JCP. Assisted reproductive technology and placenta-mediated adverse pregnancy outcomes. Obstet Gynecol. 2009;114(4):818-24.

56. Morcel K, Lavoué V, Beuchée A, Le Lannou D, Poulain P, Pladys P. Perinatal morbidity and mortality in twin pregnancies with dichorionic placentas following assisted reproductive techniques or ovarian induction alone: a comparative study. Eur J Obstet Gynecol Reprod Biol. 2010;153(2):138-42.

57. Miyake H, Iwasaki N, Nakai A, Suzuki S, Takeshita T. The influence of assisted reproductive technology on women with pregnancy-induced hypertension: a retrospective study at a Japanese Regional Perinatal Center. J Nippon Med Sch. 2010;77(6):312-7.

58. Suzuki S, Miyake H. Perinatal outcomes of elderly primiparous dichorionic twin pregnancies conceived by in vitro fertilization compared with those conceived spontaneously. Arch Gynecol Obstet. 2010;281(1):87.

59. Yang H, Choi YS, Nam KH, Kwon JY, Park YW, Kim YH. Obstetric and perinatal outcomes of dichorionic twin pregnancies according to methods of conception: spontaneous versus in-vitro fertilization. Twin Res Hum Genet. 2011;14(1):98-103.

60. Kuivasaari-Pirinen P, Raatikainen K, Hippeläinen M, Heinonen S. Adverse outcomes of IVF/ICSI pregnancies vary depending on aetiology of infertility. ISRN Obstet Gynecol. 2012

61. Bamberg C, Fotopoulou C, Neissner P, Slowinski T, Dudenhausen JW, Proquitte $\mathrm{H}$, Bührer $\mathrm{C}$, Henrich W. Maternal characteristics and twin gestation outcomes over 10 years: impact of conception methods. Fertil Steril. 2012;98(1):95-101.

62. Lučovnik M, Tul N, Verdenik I, Novak Z, Blickstein I. Risk factors for preeclampsia in twin pregnancies: a population-based matched casecontrol study. J Perinat Med. 2012;40(4):379-82.

63. Sazonova A, Kallen K, Thurin-Kjellberg A, Wennerholm UB, Bergh C. Obstetric outcome in singletons after in vitro fertilization with cryopreserved/thawed embryos. Hum Reprod. 2012;27(5):1343-50.

64. Mohammed ABF, Abdel-Maaboud M. Obstetric and neonatal outcomes of IVF versus spontaneously conceived dichorionic twins. Middle East Fertil Soc J. 2012;17(4):231-5.

65. Le Ray C, Scherier S, Anselem O, Marszalek A, Tsatsaris V, Cabrol D, Goffinet F. Association between oocyte donation and maternal and perinatal outcomes in women aged 43 years or older. Hum Reprod. 2012;27(3):896-901.

66. Werder E, Mendola P, Männistö T, O'Loughlin J, Laughon SK. Effect of maternal chronic disease on obstetric complications in twin pregnancies in a United States cohort. Fertil Steril. 2013;100(1):142-149. e142.

67. Malchau SS, Loft A, Larsen EC, Henningsen A-KA, Rasmussen S, Andersen AN, Pinborg A. Perinatal outcomes in 375 children born after oocyte donation: a Danish national cohort study. Fertil Steril. 2013;99(6):1637-1643. e1633.

68. Revello R, De la Calle M, Moreno E, Duyos I, Salas P, Zapardiel I. J Matern Fetal Neonatal Med. 2013;26(2):193-6.

69. Räisänen S, Randell K, Nielsen HS, Gissler M, Kramer MR, Klemetti R, Heinonen S. Socioeconomic status affects the prevalence, but not the perinatal outcomes, of in vitro fertilization pregnancies. Hum Reprod. 2013; 28(11):3118-25.

70. Fong A, Lovell S, Rad S, Turner A, Pan D, Ogunyemi D. 433: obstetrical complications of deliveries conceived by assisted reproductive technology in California. Am J Obstet Gynecol. 2014;210(1):S219-20.

71. Fox NS, Roman AS, Saltzman DH, Hourizadeh T, Hastings J, Rebarber A. Risk factors for preeclampsia in twin pregnancies. Am J Perinatol. 2014; 31(02):163-6.

72. Silberstein T, Levy A, Harlev A, Saphier O, Sheiner E. Perinatal outcome of pregnancies following in vitro fertilization and ovulation induction. J Matern Fetal Neonatal Med. 2014;27(13):1316-9.

73. Morency A-M, Shah PS, Seaward PGR, Whittle W, Murphy KE. Obstetrical and neonatal outcomes of triplet births-spontaneous versus assisted reproductive technology conception. J Matern Fetal Neonatal Med. 2016; 29(6):938-43. 
74. Lee MS, Cantonwine D, Little SE, McElrath TF, Parry SI, Lim K-H, Wilkins-Haug LE. Angiogenic markers in pregnancies conceived through in vitro fertilization. Am J Obstet Gynecol. 2015;213(2):212. e211-8.

75. Bay B, Ingerslev HJ, Lemmen JG, Degn B, Rasmussen IA, Kesmodel US. Preimplantation genetic diagnosis: a national multicenter obstetric and neonatal follow-up study. Fertil Steril. 2016;106(6):1363.

76. DoPierala AL, Bhatta S, Raja EA, Bhattacharya S, Bhattacharya S Obstetric consequences of subfertility: a retrospective cohort study. BJOG. 2016;123(8):1320-8.

77. Nejdet S, Bergh C, Kallen K, Wennerholm UB, Thurin-Kjellberg A. High risks of maternal and perinatal complications in singletons born after oocyte donation. Acta Obstet Gynecol Scand. 2016;95(8):879-86.

78. Zhu LL, Zhang Y, Liu YF, Zhang RJ, Wu YQ, Huang Y, Liu F, Li MG, Sun SJ, Xing LF, et al. Maternal and live-birth outcomes of pregnancies following assisted reproductive technology: a retrospective cohort study. Sci Rep. 2016;6:35141. https://doi.org/10.1038/srep35141.

79. Vikstrom J, Josefsson A, Hammar M, Bladh M, Sydsjo G. Risk of postpartum psychosis after IVF treatment: a nationwide case-control study. Hum Reprod. 2017:32(1):139-46.

80. Ben-Yaakov RD, Kessous R, Shoham-Vardi I, Sergienko R, Pariente G, Sheiner E. Fertility treatments in women who become pregnant and carried to viability, and the risk for long-term maternal cardiovascular morbidity. Am J Perinatol. 2016;33(14):1388-93.

81. Sun L, Zou G, Wei X, Chen Y, Zhang J, Okun N, Duan T. Clinical outcomes after assisted reproductive technology in twin pregnancies: chorionicitybased comparison. Sci Rep. 2016;6:26869. https://doi.org/10.1038/srep26869.

82. Rizzo G, Aiello E, Pietrolucci ME, Arduini D. Are there differences in placental volume and uterine artery Doppler in pregnancies resulting from the transfer of fresh versus frozen-thawed embryos through in vitro fertilization. Reprod Sci. 2016;23(10):1381-6.

Ready to submit your research? Choose BMC and benefit from:

- fast, convenient online submission

- thorough peer review by experienced researchers in your field

- rapid publication on acceptance

- support for research data, including large and complex data types

- gold Open Access which fosters wider collaboration and increased citations

- maximum visibility for your research: over $100 \mathrm{M}$ website views per year

At $\mathrm{BMC}$, research is always in progress.

Learn more biomedcentral.com/submissions 